Portland State University

PDXScholar

\title{
Reactions to Disability: An Empirical Investigation of Their Nature and Structure
}

Hanoch Livneh

Portland State University

Richard F. Antonak

Follow this and additional works at: https://pdxscholar.library.pdx.edu/coun_fac

Part of the Counseling Psychology Commons, Quantitative Psychology Commons, and the Social Psychology Commons

Let us know how access to this document benefits you.

\section{Citation Details}

Livneh, H., \& Antonak, R.F. (1990). Reactions to Disability: An Empirical Investigation of Their Nature and Structure. Journal of Applied Rehabilitation Counseling, 21(4), 13-21.

This Article is brought to you for free and open access. It has been accepted for inclusion in Counselor Education Faculty Publications and Presentations by an authorized administrator of PDXScholar. Please contact us if we can make this document more accessible: pdxscholar@pdx.edu. 


\section{Reactions to Disability: an Empirical Investigation of their Nature and Structure}

\section{By Hanoch Livneh, and Richard F. Antonak}

\author{
Date of Acceptance: June 10, 1990
}

\begin{abstract}
This paper describes the initial steps toward the construction of an experimental, multidimensional inventory to measure reactions to physical disability. The Relations to Impairment and Disability Inventory (RIDI) was developed to provide information on eight patterns of psychosocial reactions to disability, namely: shock, anxiety, denial, depression, internalized anger, externalized hostility, acknowledgement, and adjustment. Data are presented on initial psychometric analyses of the inventory. Analyses of the eight scales supported their homogeneity and relative independence, and the inventory's construct validity was partially documented. A moderately high degree of relationship was found between the Acknowledgement and Adjustment scales and the Acceptance of Disability (AD) scale (Linkowski, 1971), providing partial support of the inventory's criterion-related validity.
\end{abstract}

W ithin the past three decades, clinicians and researchers alike have demonstrated increased interest in the patterns of psychological reactions manifested by individuals who sustain physical impairments as a result of bodily insults (e.g., Bray, 1978; Cohn-Kerr, 1962; Fink, 1967; Frank VanValin, \& Elliott, 1987; Kruger, 1981-82; Lipowski, 1970; Shontz, 1965; Viney \& Westbrook, 1982a, 1982b; Weller \& Miller, 1977). Whereas several authors approached the study of such psychological reactions by viewing them as independent and non-sequential patterns of human behavior to the onset of sudden or insidious disabilities (e.g., Silver \& Wortman, 1980; Viney \& Westbrook, 1982b; Westbrook \& Viney, 1982), the majority of authors (e.g., Falek \& Britton, 1974; Fink, 1967; Pepper, 1977) have posited phrase or stage models 1 .

In a stage model, certain reactions are thought to occur early in the process of adaptation to disability (e.g.; shock, anxiety), and others tend to manifest themselves later (e.g., acknowledgement, adjustment). Furthermore, the appearance of more distal stages is often predicated upon the individual's ability to successfully work through the more proximal stages associated with disability onset.

Reviews of psychological patterns, reactions, phases, or stages resulting from the onset of disabling conditions (e.g., Livneh, 1986; Russell, 1981; Siller, 1976) appear to generally agree on the nature and content of these reactions but seldom on their exact sequencing, as experienced by the person. Among the most often discussed reactions are those of shock, anxiety, denial, depression, internalized anger, externalized hostility, acknowledgement, and final adjustment (e.g., Bray, 1978; Rigoni, 1977; Shontz, 1965; Weller \& Miller, 1977).

Shock is perceived as the individual's initial reaction to the onset of a sudden and severe physical impairment (e.g., spinal cord injury, myocardial infarction), or psychological trauma (e.g., diagnosis of cancer, death of a loved one). It is a reaction noted by a psychic numbness resulting from the impact of an overwhelming traumatic experience.

Anxiety is viewed as a phase of panic-stricken reaction upon initial recognition of the magnitude of the traumatic event. This reaction should not be confused with anxiety as a trait-like character concept.

Denial, considered a more problematic reaction to verify due to its subtle and often conflicting aspects, is scen as a defense mobilization against painful realization of the implication of one's condition, including the expectancy of recovery from the resulting physical impairment.

Depression, a reaction often observed among adventitiouslyimpaired individuals, is typically conceived to reflect the initial realization of the loss of one's prior physical prowess stemming from the sustained bodily insult. It is generally equated with a reactive response of bereavement for the lost body part or function. [For a more detailed discussion of the scope and exigency of the depressive reaction see Frank, et al. (1987), Howell, Fullerton, Harvey, and Klein (1981), or Turner and Wood (1985).]

Internalized anger is viewed as the exhibition of self-directed bitterness and resentment often associated with feelings of guilt and self-blame.

Externalized hostility toward other people, objects, or other aspects of the environment occurs when the person with a disability appears to be retaliating against his or her imposed physical limitations.

Acknowledgement is made up of the cognitive recognition (i.e., intellectual acceptance) of the future implications stemming from the disability and the gradual integration of the func- 
tional limitations associated with the condition into one's selfconcept.

Adjustment reflects an affective internalization (i.e., emotional acceptance) of the functional implications of an impairment into one's self-concept coupled with behavioral adaptation and social reintegration into the newly perceived life situation.

The body of information substantiating the existence of these reaction patterns consists almost invariably of descriptive accounts based on clinical observations or anecdotal impressions. The verification of this clinical lore requires, accordingly, a more empirically-based approach and the adoption of psychometrically-sound measuring instruments. Any attempt to investigate the hypothesized sequential ordering of these psychological patterns of reaction to physical disability must proceed by first demonstrating their conjectured structure (i.e., the existence of eight or a similar number of reactions to disability). In other words, the conceptual validity of these reactions must be established before the study of their temporal ordering can be logically approached.

Only scattered attempts have been made to measure the construct of adjustment to disability, and these rely almost exclusively on unidimensional scales. For example, the Acceptance of Disability (AD) scale (Linkowski, 1971; Linkowski \& Dunn, 1974), a self-report instrument which purports to measure acceptance of loss, is based on the theory of personal value changes necessitated by the onset of physical disability (Dembo, Leviton, \& Wright, 1956; Wright, 1960). Responses to individual items are summed to yield a single score representing the degree of acceptance of one's physical disability. Similarly, Osuji developed his Acceptance of Loss (AL) scale (Osuji, 1975, 1985) to quantify Dembo et al's (1956) position on the inherent personal value system changes due to the onset of physical disability. Despite a factor analysis yielding 10 separate factors (e.g., Social Loss, Spread, Obliterative Adjustment) the scale is scored by totaling a subject's responses to all 29 statements resulting in a single score ostensibly measuring one's level of adjustment to a physical disability.

The Disability Scale of Adjustment (BDSA; Bell, 1967), another univariate scale, was developed to measure a person's degree of acceptance of an orthopedic disability. The degree of acceptance is perceived to range from passive rejection, through active rejection and passive acceptance, to active acceptance. No data are provided on how resultant scale scores are to be converted to types of adjustment (e.g., passive rejection, active acceptance). Finally, Heinemann and Shontz (1984, 1985) presented the results of a Q-sort of 48 items to describe the process of adjustment following physical disability. Four theoretical stages of reaction to disability (i.e., shock, defensive retreat, acknowledgement, and adaptation) were described. In studying these stages, individuals with physically disabling conditions were required to sort items characteristic of themselves according to various predetermined self roles (e.g., usual self and ideal self) among other personal and social constructs.

The present paper describes the initial steps toward the construction of an experimental, multidimensional inventory to measure reactions to physically disabling conditions. This work was undertaken due to the limitations of existing scales; that is, the unsupported claim of unidimensionality for the construct of adjustment to disability (e.g., the scoring of the $\mathrm{AD}$ and $\mathrm{AL}$ scales and the BDSA), the narrowly targeted populations of individuals with disabilities (e.g., spinal cord injury in the BDSA), and the somewhat cumbersome and extensive measurement procedures involved (e.g., the Q-sort methodology). The purpose of this paper is twofold: first, to describe the construction of the Reactions to Impairment and Disability Inventory

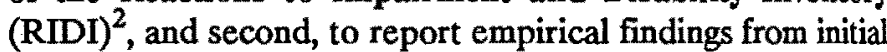
psychometric analyses of the instrument.

\section{Method}

\section{Inventory Development}

Items used for the development of the RIDI were aggregated in the following manner. (See Antonak \& Livneh, 1988, for a complete treatment of the necessary procedures for scale and inventory development.) First, an exhaustive review of the literature was conducted yielding several hundred articles, monographs, book chapters, and books dealing with psychological and social adjustment to various life crises and, more specifically, to the onset of impairments, physical disabilities, and life threatening illnesses. Second, several general measures of adjustment to disability (i.e., the BDSA, AL and $\mathrm{AD}$ scales) and specific measures of reactions assumed to be associated with various life crises and traumatic events were reviewed. Included in this latter group were the Hackett-Cassem Denial Scale (Hackett \& Cassem, 1974), the HostilityGuilt Inventory (Buss \& Durkee, 1957), the Beck Depression Inventory (Beck, 1967), the Rating Scale for Depression (Hamilton, 1960), the MMPI Depression Scale, the Self-Rating Depression Scale (Zung, 1965), the S-R Inventory of Anxiousness (Endler, Hunt, \& Rosenstein, 1962), the Manifest Anxiety Scale (Taylor, 1953), the MMPI Anxiety Index (Welsh, 1952), the Affect Adjective Check List (Zuckerman, 1960), the Symptom Check List-90 (Derogatis, Lipman, \& Covi, 1973), and the Millon Behavioral Health Inventory (Millon, Green, \& Meagher, 1981).

Based on the review of these sources, over 300 items, phrases, or statements, suggesting various types of psychological reactions to disabling conditions, or major life crises, werex extracted. In addition, interviews with several rehabilitation experts were conducted and suggested items were incorporated into the list. A careful review of the list of items was conducted with the objective of eliminating items which were deemed redundant, ambiguous, or highly specific reactions manifested only by certain disability groups (e.g., "since the loss of my eyesight I find myself avoiding sighted people"). When necessary, items were rephrased to capture more meaningfully a particular reaction. These procedures resulted in the construction of a list of approximately 200 items which were then sorted into one of eight reactions to disability categories: shock, anxiety, denial, depression, internalized anger, externalized hostility, acknowledgement, and adjustment. Items that did not clearly belong to any of the predetermined categories, or which were judged to belong to more than one category, were reworded or discarded. These procedures yielded a 143-item list. 
The list of items was then mailed to 12 nationally-known experts and to three local rehabilitation psychologists for their comments. More specifically, the experts were requested to: (a) specify, for each item, if it belonged only marginally, belonged, or definitely did not belong to its assigned disability reaction category (i.e., Did the item convey the essence of the specific reaction to which it was assigned?); and (b) comment on the items or phrases portraying these reactions and add any not included in the list presented. The final list of reactions comprising the RIDI at that stage of its development included 95 items based on the responses and suggestions made by the panel of experts.

The final step in the content validation of the RIDI included limited field testing of the instrument, via personal interviews of a sample of individuals with various physically disabling conditions (e.g., blindness, spinal cord injury, amputation, myocardial infarction, cancer). Based on responses and suggestions obtained during these interviews the RIDI was further revised and its number of items reduced to 90 . These 90 items were then arranged in a random order on the final inventory.

The RIDI in its present form consists of eight self-report summated rating scales measuring personal reactions to the onset of a physical impairment or a disabling medical condition. Each ifem on the RIDI is rated on a 4-point scale, ranging from 1-Never (to signify the reaction was never experienced), through 2--Seldom (the reaction was experienced only on rare occasions; less than four times per month), to 3--Sometimes (the reaction was experienced occasionally; approximately five to ten times per month), to 4-Often (the reaction was experienced repeatedly; more than ten times per month). responses to the items within each of the eight scales are summed to yield a global score for each scale.

The eight scales are: Shock ( 8 items; examples include "I cannot absorb everything that is happening to me," "I feel frozen, unable to move"), Anxiety (11 items; "I am about to go to pieces," "It is difficult to keep my mind on one thing"), Denial (10 items; "God will cure me, if I improve my behavior and follow His ways," "I believe that my physical impairment will go away by itself"), Depression (14 items; "I feel that there is nothing I can do to help myself," "My family would be better off if I were dead"), Internalized Anger ( 8 items; "When I look back at what has happened to me, I feel bitter," "My impairment must be a punishment for something I did in the past"), Externalized Hostility (12 items; "I find myself arguing more with people," "I feel like striking out at someone"), Acknowledgement (12 items; "I am interested in getting socially involved with other people," "I know my limitations and have learned how to deal with them"), and Adjustment (15 items; "Although I am restricted in certain ways, there is still much I am able to do," "Everything in my life is coming together again").

\section{Subjects}

Empirical validation of the RIDI involved analyses of the responses obtained from 214 people with various types of physical disabilitiès. Briefly, the sample was composed of 80 females and 134 males. Respondent's ages ranged from 16 to 83 years $(M=43.9$ years, $S D=17.9$ years). Ninety-four percent of them were white with the remaining approximately equally dis- tributed among people with Black, Hispanic, and Oriental heritages. Most respondents were either single (39.3\%) or married $(36.0 \%)$, while divorced $(12.6 \%)$, widowed $(8.9 \%)$, and separated (3.3\%) individuals comprised the remaining marital groups. Educational levels attained by the respondents ranged from third grade to individuals holding a master's degree. Most $(33.2 \%)$ were high school graduates, followed by individuals with a 2-year college education (12.1\%), and college graduates $(12.1 \%)$.

Primary impairments included spinal cord injury (34.6\%), cerebrovascular accident $(12.1 \%)$, multiple sclerosis $(7.0 \%)$, myocardial infarction (7.0\%), and amputation (6.1\%). In all, over 30 types of impairments were specified by the respondents. Age of onset ranged from impairments associated with diseases detected at birth to those occurring in advanced age ( 80 years and older). Most impairments, however, appeared to originate in the 17 to 50 year age range. Finally, length of time since onset of impairment varied from less than 1 month to 64 years ( $M=11.5$ years, $S D=10.5$ years, $M d=7$ years).

\section{Procedure}

Administrators, directors, and other rehabilitation personnel in several hospitals, rehabilitation facilities, state vocational rehabilitation divisions, and services for the blind and visually impaired in the southeastern New England region were reached by mail and telephone by the senior author to explain the purposes of the study. Those agreeing to participate were later visited personally and given specific instructions as to the nature of the study, the measures to be used, and data collection procedures. Designated data collection personnel (i.e., psychologists, nurses, occupational therapists, physical therapists, social workers, rehabilitation counselors, physiatrists) were briefed on the purposes of the study, the nature of the measuring instrument, and the administration procedures to be followed.

Two modes of data collection were adopted. First, direct administration of the RIDI was employed for respondents in inpatient facilities (i.e., hospitals, rehabilitation units) who were requested to return them by the end of the day. When permissible, instruments were administered by rehabilitation personnel in small group settings. Second, clients of non-in-patient rehabilitation facilities (e.g., DVR) were mailed the instrument with a self-addressed, stamped envelope accompanied by a cover letter explaining the purpose of the study and encouraging them to complete the RIDI and return it to their case manager (e.g., rehabilitation counselor) within a week's time. Participants in these agencies were randomly sampled from various types of caseloads (e.g., spinal cord injury, blindness, general) to assure appropriate representation of disabling conditions. Instrument return rates varied widely for the different participating rehabilitation case managers and types of disabling conditions, with an average return rate of approximately $60 \%$.

For this inventory development study, the RIDI instructions were written to ask the respondents to rate each item twice. First, they were asked to estimate the extent to which they experienced each reaction in the past, defined as "any time during the period immediately following the onset of the impairment 
or disability until recently, but not including the past month." Second, they were asked to rate the extent to which they experienced each reaction in the present, defined as "during only the last month." The reason for the separation of responses to past and present reactions was the methodological need to control the possible confounding between present or ephemeral reactions associated with daily hassles, uplifts, or short-term life events, and the more indelible effects of disability onset (see, for example, Folkman \& Lazarus, 1980; Kanner, Coyne, Schaefer, \& Lazarus, 1981).

RIDI instructions clearly specified that there were no right or wrong answers. This was also verbally conveyed to participants by the rehabilitation personnel administering the inventory in the in-patient settings. In addition, participants were encouraged to respond to all statements as honestly as possible and were assured of complete anonymity of their responses. No time limits were set.

\section{Statistical Analyses}

Means and standard deviations were calculated for all 90 RIDI items separately for both past (RIDI-Past) and present (RIDI-Present) reactions ${ }^{3}$. Similarly, means and standard deviations were computed for the eight hypothesized scales. Pearson product-moment correlation coefficients were calculated among all RIDI items and additionally among the eight scales. A series of exploratory factor analytic procedures were. then applied to the correlation matrices of the RIDI items. Internal consistency coefficients (Cronbach's alpha) were calculated for both the original eight scales and the factor analytic derived scales. The degree of relationship between the eight original RIDI scales and various demographic variables (e.g., gender, age, education, marital status, age of disability onset, duration since disability onset) were examined using a series of multiple discriminant analysis procedures. The criterion-related validity of two of the RIDI scales (acknowledgement and Adjustment) was investigated by correlating the scores of a subsample of 30 individuals on these two scales with their scores on the Acceptance of Disability scale which was administered separately.

\section{RESULTS}

\section{Scale Analyses}

\section{Factor Analyses}

Bartlett's test of sphericity (1950) for the differential significance of the item correlation matrix from an identity matrix yielded a $\chi^{2}$ value of $11,722.42, p<.001$. The resultant correlation matrix was studied with various factor analytic procedures. It was reasoned that, in order to adequately investigate the structure of the RIDI in these initial stages of its development, a series of exploratory, rather than confirmatory, factor analytic procedures should be applied to the data (see, for example, Comrey, 1978), including different extraction methods (i.e., principal components, alpha, principal factors), forced extraction of various numbers of factors using different analytic criteria (i.e., magnitude of the eigenvalues, the scree test, variance ratios), and terminal rotation of the factors using different criteria (i.e., orthogonal rotation with a varimax criterion, oblique rotation with the delta criterion set to yield various degrees of relatedness of the factors).

After careful review of the results of the different factor analyses, an orthogonally-rotated seven factor principal components solution, accounting for $44.3 \%$ of the variance in the data, was chosen as the most appropriate, parsimonious, interpretable, and psychologically meaningful representation of the RIDI data. Items were assigned to a particular factor only when the item-factor correlation equalled or exceeded .35 , and when the correlation of the item with any of the remaining six factors was less than $\mathbf{3 5}$.

The first factor, accounting for $21.5 \%$ of the extracted variance, was a combined Acknowledgement-Adjustment factor. Of the 27 items on this factor, all of the original Adjustment scale items $(n=15)$ and 9 of the 12 original Acknowledgement scale items loaded on it. Highest loaded items included "I am exploring my strengths and abilities" $(r=.70)$, "Although I am restricted in certain ways, there is still much that I am able to do" $(r=.69)$, and "Despite my physical impairment, I can still be a successful person" $(r=68)$.

The second factor, accounting for $8.2 \%$ of the variance, coalesced the Depression and Internalized Anger scales into a single factor. Nine Depression scale items (of the 14 included) and five Internalized Anger scale items (of the 8 listed) made up this factor. The remaining five items were from the Shock and Anxiety scales. Highest loaded items included "I feel discouraged about the future" $(r=.76)$, "I find myself asking Why did this happen to me?" $(r=.71)$, and "My life is empty" $(r=.61)$.

The third factor was clearly an Externalized Hostility factor accounting for $4.0 \%$ of the variance. Eight of the Externalized Hostility scale items loaded on this factor. The remaining seven items were gathered inconsistently from four separate scales. The most salient items of this factor included "I feel like striking out at someone" $(r=.66)$, "I feel like screaming at others" $(\mathrm{r}=.66)$, and "I find myself arguing more with people" $(r=60)$.

The fourth factor, with eight items and explaining $3.0 \%$ of the variance, appeared to be a combined Externalized Hostility (four items) and Anxiety (three items) factor. Its most prominent items included "Others expect me to prove myself more that they expect an able-bodied person to do so" $(r=.62)$, "Since I became physically impaired, I have periods of nausea" $(\mathbf{r}=.55)$, and "I am so restless that I cannot sit still" $(r=.48)$. The fifth factor, somewhat related to its predecessor, is a more pure somatic-symptomatology anxiety factor (five of the seven items are Anxiety scale items), explaining $2.7 \%$ of the variance. Items most heavily loaded on this factor were "Since I became physically impaired, I have periods of breathlessness" $(r=.66)$, "Since I became physically impaired, I have periods when my heart pounds" $(r=.63)$, and "I have periods of hot and cold spells" $(r=61)$.

The final two factors, 6 and 7, were composed mainly of the Denial scale items. Factor 6 , explaining $2.4 \%$ of the variance, loaded on five items, the most significant of which were "I will soon be just like I was before" ( $r=.67)$, "I am certain that I will be completely cured" $(r=.66)$, and "I believe that my physical impairment will go away by itself" $(r=.61)$. Factor 7 , also explaining $2.4 \%$ of the variance, was a doublet loading on "I 
believe that nothing is wrong with me" $(\mathbf{r}=.52)$, and "If I were nicer to people, I would regain my abilities" $(r=.51)$. Whereas factor 6 seems to reflect an attitude of faise or unrealistic hope, factor 7 suggests the more typical reaction of denial combined with a return to normalcy, a bargaining attitude.

\section{Item and Scale Analyses}

To establish the internal consistency of both the eight original RIDI scales and six of the seven factor analytic-derived scales (Denial II was omitted since only two items loaded on it), Cronbach's alpha coefficients were calculated (see Table 1). Both the original scales and the factor analytic-derived scales possess an acceptable degree of internal consistency, with

\section{Validity Analyses}

\section{Content Validity}

Content, or substantive, validity of the RIDI scales was discussed in the inventory development section. Further evidence of the validity of the inventory's scales can be seen in the results of the exploratory factor analyses and the scale consistency investigations.

\section{Construct Validity}

It was hypothesized that the RIDI scale scores should be able to discriminate among certain respondent characteristics (e.g., age of onset of disability, duration since onset of disability), while other characteristics should manifest no relationship to

Table 1

Alpha, Item-Scale, and Inter-Item Correlation Coefficients of Original and Factor-Analytic Derived Scales

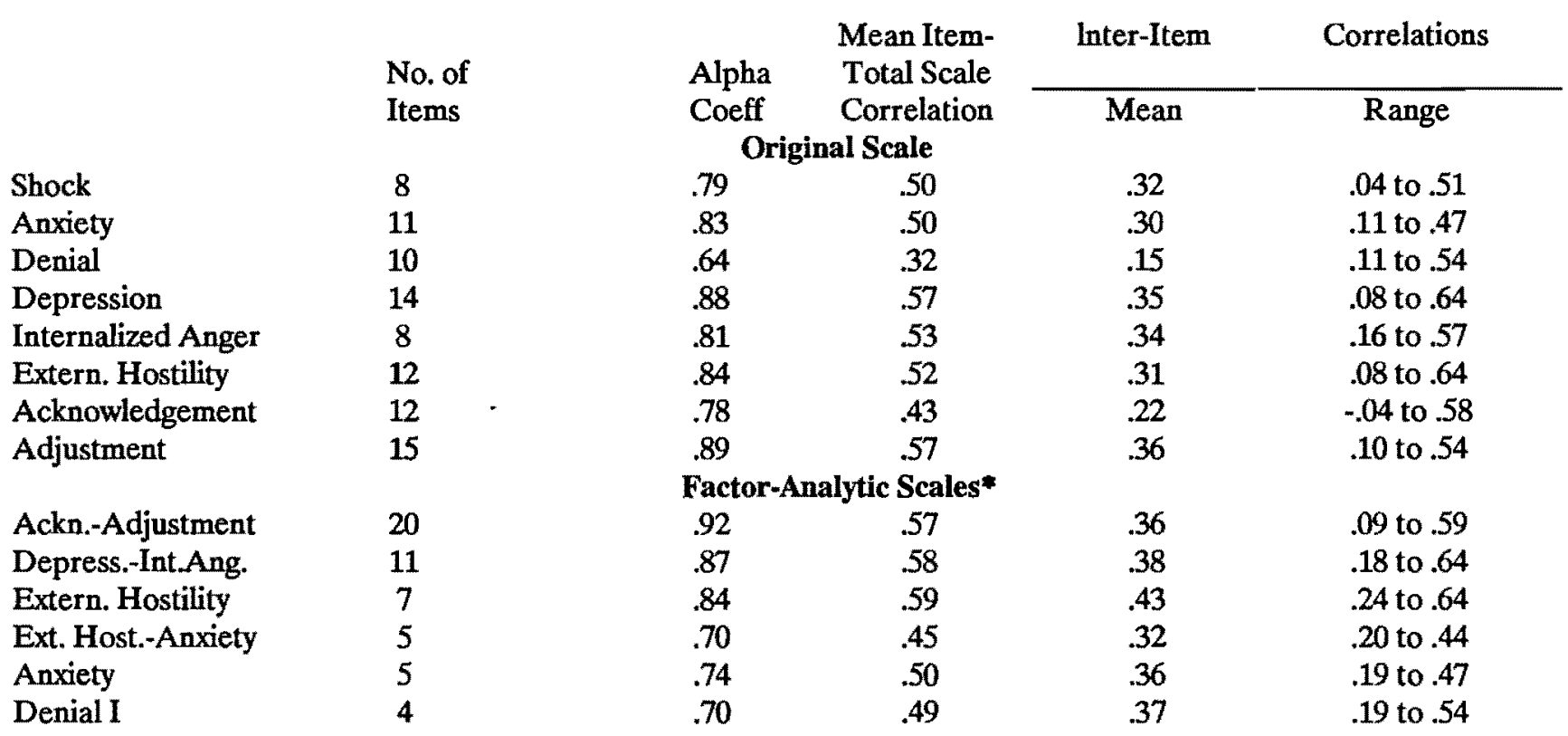

*Only items from the specified original scales loading at least .35 on each factor were included in the analyses.

values of at least 78 for all of the former scales except the Denial scale, and values of at least .70 for all of the latter scales.

The six factor analytic-based scales appear to have only moderately increased the internal stability of the original scales, while compromising their clinically-derived conceptual clarity. Although this finding may be partially due to the smaller number of items included on the last four factors, examination of Table 1 reveals that only minor improvements in both mean item-total scale and mean inter-scale correlation coefficients were achieved. The mean RIDI scale scores and standard deviations, and the correlations between pairs of scales are presented in Table 2. The matrix of inter-scale correlations, while not an identity matrix, contains values of the desired magnitude. scores on the RIDI scales (e.g.,gender, present age, education). Accordingly, means and standard deviations of each of the eight scales were analyzed to determine their relationships to several personal and demographic characteristics of the respondents.

Gender. Results of analyses of variance yielded only one significant difference in scale means between male and female respondents -- for the Anxiety scale, $F(1,184)=4.93, p=.028$. Gender differences in the remaining RIDI scale mean scores were not statistically significant.

Age. Age of respondents was significantly correlated with only Internalized Aggression scale scores $(\mathbf{r}=-.23, \mathbf{p}<.01)$, with older respondents reporting having experienced this reaction less frequently then younger respondents.

Education: Educational level of the respondents did not correlate significantly with any of the eight RIDI scales. 
Table 2

Inter-Scale Correlations, Means and Standard Deviations of the Eight RIDI Scales

$\begin{array}{lllllllll} & \text { Sh Anx } & \text { Den } & \text { Dep } & \text { IA } & \text { EH } & \text { Ack } & \text { Adj } \\ \text { Shock (Sh) } & .79 & .63 & .15 & .70 & .72 & .57 & -.18 & -.37 \\ \text { Anxiety (Anx) } & .83 & .06 & .67 & .63 & .64 & -.10 & -.26 \\ \text { Denial (Den) } & & .64 & .03 & .05 & .13 & .21 & .23 \\ \text { Depression (Dep) } & & .88 & .78 & .65 & -.27 & -.51 \\ \text { Intern. Anger (IA) } & & & .81 & .72 & -.23 & -.43 \\ \text { Extern.Hostil.(EH) } & & & & .84 & -.09 & -.29 \\ \text { Acknowledgement } & & & & & .78 & .79 \\ \text { Adjustment } & & & & & & & .89 \\ \text { Scale Mean } & 17.32 & 21.71 & 19.02 & 29.76 & 17.05 & 23.98 & 30.7838 .04 \\ \text { SD } & 6.23 & 7.34 & 5.06 & 10.48 & 6.25 & 8.27 & 7.29 & 11.07\end{array}$

Note. Values on the main diagonal of the correlation matrix are Cronbach's alpha reliability coefficients. $\mathbf{N}=$ 185.

Age of disability onset. Respondents were classified into one of four age of disability onset groups: childhood and adolescence ( 0 to 15 years, $\mathbf{n}=30$ ), young adulthood ( 16 to 30 years, $\mathbf{n}=67$ ), adulthood ( 31 to 50 years, $n=56$ ), and older age (51 years and above, $\mathbf{n}=32$ ). A stepwise discriminant function analysis was performed to compare scale scores for the four age groups. It was reasoned that due to differential levels of selfconcept development and past life experiences among the respondents in the four groups (in particular, the diversity in maturation processes, coping strategies, stages of cognitive development, and the availability of support systems), divergent patterns of reactions to disability would be detected in the sample. More specifically, it was hypothesized that individuals who were younger adults or adults, upon onset of disability, would manifest higher scores (i.e., more pronounced reactions) on the scales of Anxiety, Depression, Internalized Anger, and Externalized Hostility, than would children and older adult respondents.

The four-group discriminant function analysis yielded only one significant function; Wilks' $\chi$ (lambda) $=.81 \quad\left(\chi^{2}=37.34\right.$, $\mathbf{d f}=15, \mathbf{p}=.001), \mathbf{R}_{c}=.37$. The remaining two functions failed to significantly discriminate among the groups (19\% and $10 \%$ of variance accounted for between groups, respectively, $p$ 's $>.15)$. Inspection of the group centroids $(.50, .26,-.19$, and -.67 for the four age groups, respectively), revealed that the first discriminant function placed the four groups on a continuum with maximal separation noted between the youngest and the oldest age of disability onset groups, with the other groups falling between these two.

Five RIDI scales contributed to the discriminant equation: The variables, rank ordered as to their standardized canonical discriminant coefficients, were Anxiety (-1.37), Externalized Hostility (0.65), Internalized Anger (0.60), Adjustment (0.52)

Table 3

RIDI Scale Means and F Ratios for Groups of Age of Disability Onset and Chronicity of Disability Age of Disbility Onset

Group Means

\begin{tabular}{|c|c|c|c|c|c|}
\hline & Child & Young & \multicolumn{3}{|c|}{ Older } \\
\hline RIDI Scale & Adol & Adult & Adult & Adult & $\mathbf{F}$ \\
\hline Shock & 15.37 & 17.84 & 18.07 & 16.75 & 1.51 \\
\hline Anxiety & 18.20 & 21.93 & 22.80 & 22.66 & $2.99^{*}$ \\
\hline Denial & 18.67 & 19.52 & 18.87 & 18.53 & 0.38 \\
\hline Depression & 26.97 & 30.96 & 31.61 & 26.62 & $2.61^{*}$ \\
\hline Internalized Anger & 15.73 & 18.46 & 17.16 & 15.16 & $2.64^{*}$ \\
\hline Extern. Hostility & 23.00 & 25.54 & 23.98 & 21.66 & 1.80 \\
\hline Acknowledgement & 31.67 & 30.96 & 30.68 & 29.78 & 0.36 \\
\hline Adjustment & 41.20 & 37.82 & 36.61 & 38.03 & 1.14 \\
\hline \multicolumn{6}{|c|}{$\begin{array}{l}\text { Chronicity of Disability } \\
\text { Group Means }\end{array}$} \\
\hline RIDI Scale & Short & Medium & Long & Very Long & $\mathbf{F}$ \\
\hline Shock & 18.97 & 17.77 & 17.45 & 14.61 & $3.45^{*}$ \\
\hline Anxiety & 22.25 & 22.15 & 22.21 & 19.69 & 1.13 \\
\hline Denial & 18.70 & 19.28 & 19.12 & 18.81 & 0.13 \\
\hline Depression & 29.52 & 29.94 & 31.59 & 26.89 & 1.49 \\
\hline Internalized Anger & 17.55 & 17.55 & 18.11 & 14.14 & $3.46^{*}$ \\
\hline Extern. Hostility & 25.92 & 23.75 & 24.12 & 21.94 & 1.50 \\
\hline Acknowledgement & 31.12 & 30.30 & 30.59 & 31.42 & 0.21 \\
\hline Adjustment & 36.17 & 38.42 & 36.62 & 41.75 & 2.09 \\
\hline
\end{tabular}

${ }^{*} \mathrm{p}<.05, \mathrm{df}=3,181$ 
and Depression ( 0.40$)$. As these standardized coefficients indicate, the reactions of anxiety and both externalized and internalized anger were the most salient in differentiating among the four groups defined by age of disability onset.

Univariate F tests with Scheffe' post hoc tests were used to compare the four group means on each scale. (Scale means are reported in Table 3.) Subjects in group 1 (children and adolescents) scored significantly lower than did subjects in the remaining three groups on the Anxiety scale. Groups 1 and 4 scored significantly lower than the two middle age of disability onset groups on the Internalized Anger scale. Finally, the two extreme groups scored significantly lower that the two middle groups on the Depression scale.

Chronicity of disability. Respondents were classified into one of four chronicity of disability (length of time since disability first occurred) groups: short (less than 24 months, $n=40$ ), medium ( 25 to 72 months, $\mathbf{n}=53$ ), long ( 73 to 180 months, $\mathbf{n}=56$ ), and very long (181 months and longer, $\mathbf{n}=36$ ). A stepwise discriminant function analysis was performed to compare the four groups on each of the RIDI scales. It was speculated that gradually increasing time periods since onset of disability would exert differential influences on participants' experiences and, accordingly, result in different patterns of reactions to their acquired conditions. That is, as the differences in chronicity of disability became more pronounced, so would the patterns of experienced reactions.

The four-group discriminant function analysis yielded only one significant function; Wilks' $\chi=.80 \quad \alpha^{2}=38.31$, df $=18$, $p=.003), R_{c}=.35$. The remaining two functions failed to significantly discriminate the four groups. Inspection of the group centroids $(-.57, .05,-.02$, and .59 for the four age groups, respectively), revealed that the first discriminant function resulted in a maximal separation between the two extreme groups of shortest and longest duration since onset of disability, with the other two groups falling in close proximity to each other in the middle.

Six scales contributed to the discriminant equation. These scales, in order of their standardized discriminant coefficients, were: Adjustment (1.28), Depression (1.10), Acknowledgement (-0.92), Shock (-0.76), Internalized Anger (-0.29), and Externalized Hostility $(-0.23)$. As these coefficients suggest, the reactions of adjustment, depression, and acknowledgement are the most salient in discriminating among the four groups separated according to duration of time since disability onset.

Univariate F tests with Scheffe' post hoc tests were used to compare the four chronicity group means on each scale. (Scale means are reported in Table 3.) Significant differences were obtained for the Shock, and Internalized Anger. Subjects in group 4 scored significantly lower than subjects in the remaining three groups on both the Shock and Internalized Anger scales (i.e., they recalled experiencing less shock and anger as a result of their disability onset). The scores on the Adjustment scale demonstrated a reverse trend whereby group 4 subjects scored higher (i.e., reported better adjustment) than subjects in the shorter chronicity of disability groups.

\section{Criterion-related Validity}

To study the criterion-related external validity of the RIDI, respondents' score on the inventory were correlated with their scores on the Acceptance of Disability (AD) scale (Linkowski, 1971). Since scores on only two RIDI scales (i.e., Acknowledgement and Adjustment) are conceptually tied to scores on the AD scale, a subsample of 30 individuals with duration of disability of at least 3 years was selected for these analyses. This sample of respondents was administered both instruments, in random order, and their scores on both measures were correlated. The correlation for the combined 27-item Acknowledgement-Adjustment scale with the $A D$ scale was 68 . This result indicates that the combination of the Acknowledgement and Adjustment scales of the RIDI measures a common construct to the $\mathrm{AD}$ scale with approximately $45 \%$ of the variance in the RIDI scores accounted for by AD scale scores. Correlation of the AD scale scores with five of the remaining six RIDI scales ranged from -.29 to .20 (i.e., explaining less than $10 \%$ of the common variance), while the $\mathrm{AD}$ scale's correlation with the RIDI Depression scale (its logical antithesis) was -.39 .

\section{DISCUSSION}

The present study was an effort to investigate the substance and structure of psychological reactions to the onset of disabling conditions. The experimental instrument developed for these purposes, the Reactions to Impairment and Disability Inventory displayed satisfactory psychometric properties. The eight RIDI scales were shown to have acceptable levels of internal reliability (i.e., homogeneity), although the specificity of the scales (Horst, 1966) still needs to be demonstrated. That is, although inter-item and item-total scale correlations were high within each scale, the eight original scales do not yet demonstrate uniformly acceptable low bivariate correlations.

Content and construct validities of the eight scales were marginal but considered adequate at this stage of their development. The inventory's factorial structure requires further exploration in light of the discrepancy noted between the theoretical-clinical structure of reactions to disability and the resultant empirically-derived structure of the RIDI data. The blending of several of the original scales into single factors (i.e., Acknowledgement-Adjustment, Depression-Internalized Anger, Externalized Hostility-Anxiety), although defensible on empirical grounds, still runs counter to theoretical conceptualizations and clinical observations (Bray, 1978; Krueger, 1981-1982; Livneh, 1986; Verwoerdt, 1972). Also, it was expected that a certain degree of overlap existed between depression-type and internalized anger-type reactions, and between acknowledgment-type and adjustment-type reactions due to: (a) their theorized temporal proximity, (b) the similarity of clinical manifestations they exhibit during the process of adaptation to disability sequelae, and (c) the wide range of disabling conditions studied.

At its present developmental stage, the RIDI may sacrifice a degree of empirical soundness for conceptual clarity. For example, the eight a priori reactions to disability scales have been retained in the present version of the RIDI, despite the inability of the analytic procedures used in these analyses to recover the exact hypothesized structure. On the one hand, there is a sub- 
stantial clinical literature that supports the existence of these phases. On the other hand, the instability of the analytic results in this investigation renders total reliance on these preliminary psychometric findings unwise. Revisions of the RIDI which are currently underway may result in a shorter version with sounder psychometric properties of the items and scales, and a clearer factorial structure. A final decision regarding the existence of the eight hypothesized stages of reaction to disability must await an examination of the results of future analyses.

The respondents' ability to recall certain experiences associated with disability onset may place limitations on the accuracy of their reported reactions. Clearly, individuals who sustained the onset of a disabling condition 50 or more years ago may have difficulty recalling certain initial reactions to it, often confounding them with non-onset-of-disability-specific reactions, while people with more recent onset of disability may not.

The self-report format of the RIDI, although not more fallible than other methods of inquiry (see, for example, Shrauger \& Osberg, 1981), will necessitate verification by other independent methods, such as significant others' reports, or behavioral observations by independent judges. The possibility of confounding and intruding effects of socially desirable responding, common with self-report measures, will be examined in future studies.

One of the advantages of the RIDI is its multidimensional format which enables the study of different profiles, or patterns, of reactions to disability concurrently. Another potential strength of the inventory is its heuristic value for investigating the hierarchical properties of the hypothesized reactions encountered in clinical practice (i.e., the phases of adaptation to disability). Such investigations are currently underway and will be reported in the future.

The RIDI also has the potential to generate useful information in studies which propose to investigate people's coping strategies with unexpected, adverse life occurrences, such as catastrophic environmental incidents (e.g., fires, earthquakes, floods) or with other daily stressful events. Insight may be gained on the nature of the cognitive, affective, and behavioral strategies individuals resort to when faced with such stressproducing situations and the longitudinal processing involved in appraising and coping with these tragic situations. [For reports of previous work of this type, see Billings \& Moos, 1982, 1984; Folkman \& Lazarus, 1988; Folkman, Lazarus, Pimley \& Novacek, 1987; Lazarus, 1981.]

In its present form, the RIDI is strictly an experimental tool for researchers. Attempts to use it as a clinical or diagnostic instrument are clearly unwarranted until it undergoes further conceptual elaborations and psychometrics revisions. It is seen as a preliminary investigative tool in the study of the development, structure, and correlates of reactions to the onset of physically disabling conditions.

\section{References}

Antonak, R.F., \& Livneh, H. (1988). The measurement of attitudes toward people with disabilities: Methods, psychometrics, and scales. Springfield, IL: C.C. Thomas.

Bartlett, M.W. (1950). Tests of significance in factor analysis. British Journal of Psychology, 3, 77-85.
Beck, A.T. (1967). Depression: Cause and treatment. Philadelphia, PA: University of Pennsylvania Press.

Bell A.H. (1967). Measure for adjustment of the physically disabled. Psychological Reports, 21, 773-778.

Billings, A.G., \& Moos, R.H. (1982). Stressful life events and symptoms: A longitudinal model. Health Psychology, 1, 99 . 117.

Billings, A.G., \& Moos, R.H. (1984). Coping, stress, and social resources among adults with unipolar depression. Journal of Personality and Social Psychology, 46, 877-891.

Bray, G.P. (1978). Rehabilitation of spinal cord injured: A family approach. Journal of Applied Rehabilitation Counseling, 9, 70-78.

Buss, A.H., \& Durkee, A. (1957). An inventory for assessing different kinds of hostility. Journal of Consulting Psychology, 21, 343-349.

Cohn-Kerr, N. (1961). Understanding the process of adjustment to disability. Journal of Rehabilitation, 27, 16-18.

Comrey, A.L. (1978). Common methodological problems in factor analytic studies. Journal of Consulting and Clinical Psychology, 46, 648-659.

Dembo T., Leviton, G.L., \& Wright, B.A. (1956). Adjustment to misfortune - A problem of social-psychological rehabilitation. Artifical Limbs, 3, 4-62.

Derogatis, L.R., Lipman, R.S., \& Covi, L. (1973). SCL-90: An outpatient psychiatric rating scale -2 preliminary report. Psychopharmacology Bulletin, 9, 13-28.

Endler, N.S., Hunt, J.M., \& Rosenstein, A.J. (1962). An S-R inventory of anxiousness. Psychological Monographs, 76, 1-33 (whole no. 536).

Falek, A., \& Britton, S. (1974). Phases in coping: The hypothesis and its implications. Social Biology, 21, 1-7.

Fink, S.L. (1967). Crisis and motivation: A theoretical model. Archives of Physical Medicine and Rehabilitation, 48, 592597.

Folkman, S., \& Lazarus, R. (1980). An analysis of coping in a middle-aged community sample. Journal of Health and $\mathrm{So}^{\text {- }}$ cial Behavior, 21, 219-239.

Folkman, S, \& Lazarus, R.S. (1988). Coping as a mediator of emotion. Journal of Personality and Social Psychology, 54, 466-475.

Folkman, S., Lazarus, R.S., Pimley, S., \& Novacek, J. (1987). Age differences in stress and coping processes. Psychology and Aging, 2, 171-184.

Frank, R.G., VanValin, P.H., \& Elliott, T.R. (1987). Adjustment to spinal cord injury: A review of empirical and nonempirical studies. Journal of Rehabilitation, 53, 43-48.

Hackett, T.P., \& Cassem, N.H. (1974). Development of a quantitative rating scale to assess denial. Journal of Psychosomatic Research, 18, 93-100.

Hamilton, M. (1960). A rating scale for depression. Journal of Neurosurgery and Psychiatry, 23, 56-62.

Heinemann, A.W., \& Shontz, F.C. (1984). Adjustment following disability: Representative cases. Rehabilitation Counseling Bulletin, 28, 3-14.

Heinemann, A.W., \& Shontz, F.C. (1985). Methods of studying persons. The Counseling Psychologist, 13, 111-125.

Horst, P. (1966). Psychological measurement and prediction. Belmont, CA: Wadsworth.

Howell, T, Fullerton,D.T., Harvey, R.F. \& Klein, M. (1981). Depression in spinal cord injured patients. Paraplegia, 19, 284-288.

Kanner, A.D., Coyne, J.C., Schafer, C., \& Lazarus, R.S. (1981). Comparison of two modes of stress management: Daily hassles and uplifts versus major life events. Journal of Behavioral Medicine, 4, 1-39.

Krueger, D.W. (1981-1982). Emotional rehabilitation of the physical rehabilitation patient. International Journal of Psychiatry in Medicine, 11, 183-191.

Lazarus, R.S . (1981). The stress and coping paradigm. In C. Eisdorfer, D. Cohen, A. Kleinman, \& P. Maxim (Eds.), Models for clinical psychopathology (pp.177-214). New York: SP Medical and Scientific Books.

Linkowski, D.C. (1971). A scale to measure acceptance of disability. Rehabilitation Counseling Bulletin, 14, 236-244. 
Linkowski, D.C., \& Dunn, M.A. (1974). Self-concept and acceptance of disability. Rehabilitation Counseling Bulletin, 18, 28-32.

Lipowski, ZJ. (1970). Physical illness, the individual and the coping process. International Journal for Psychiatry in Medicine, 1, 91-102.

Livneh, H. (1986). A unified approach to existing models of adaptation to disability. Part I: A model of adaptation, Journal of Applied Rehabilitation Counseling, 17, 5-16, 56.

Livneh, H. (1987). Person-environment congruence: $A$ rehabilitation perspective. International Journal of Rehabllitation Research, 10, 3-19.

Millon, T., Green, C.J., \& Meagher, R.B. (1981). Millon Behavior Health Inventory Manual. Minneapolis, MN: National Computer Systems.

Osuji, O.N. (1975). Acceptance of loss -- Quantification of the concept. Rehabilitation Digest, 6, 3-8.

Osuji, O.N. (1985). Personality factors in acceptance of loss among the physically disabled. The Psychological Record, 35, 23-28.

Pepper, G.A. (1977). The person with a spinal cord injury: Psychological care. American Journal of Nursing, 77, 13301336.

Rigoni, H.C. (1977). Psychological coping in the patient with spinal cord injury. In D.P. Pierce \& V.H. Nickel (Eds.), The total care of spinal cord injuries (pp.229-307). Boston: Little, Brown.

Russell, R.A. (1981). Concepts of adjustment to disability: An overview. Rehabilitation Literature, 42, 330-338.

Shontz, F.C. (1965). Reactions to crisis. The Volta Review, 67, 364-370.

Shrauger, J.S, \& Osberg, T.M. (1981). The relative accuracy of self-predictions and judgments by others in psychological assessments. Psychological Bulletin, 90, 322-351.

siller, J. (1976). Psychological aspects of physical disability. In J. Meislin (Ed.), Rehabilitation medicine and psychiatry (pp.455-484) Springfield, IL: C.C. Thomas.

Silver, R.L., \& Wortman, C.B. (1980). Coping with undesirable life events. In J. Garber \& M.E.P. Seligman (Eds.), Human helplessness: Theory and applications (pp.279-340). New York: Academic Press.

Taylor, J.A. (1953). A personality scale of manifest anxiety. Journal of Abnormal and Social Psychology, 48, 285-290.

Turner, R.J., \& Wood, D.W. (1985). Depression and disability: The stress process in a chronically strained population. In J.R. Greenley (Ed.), Research in community and mental health: Vol. 5 (pp.77-109). Greenwich, CT: JAI Press.

Verwoerdt, A. (1972). Psychopathological responses to the stress of physical illness. Advances in Psychosomatic Medicine, 8, 119-141.

Viney, L.L, \& Westbrook, M.T. (1981). Psychological reactions to chronic illness-related disability as a function of its severity and type. Journal of Psychosomatic Research, 25, 513-523.

Viney, L.L., \& Westbrook, M.T. (1982a). Coping with chronic illness: The mediating role of biographic and illness-related factors. Journal of Psychosomatic Research, 26, 595-605.

Viney, L.L., \& Westbrook, M.T. (1982b). Patients psychological reactions to chronic illness: Are they associated with rehabilitation. Journal of Applied Rehabilitation Counseling, $13,38-44$

Weller, D.J., \& Miller, P.M. (1977). Emotional reactions of patient, family, and staff in acute-care period of spinal cord injury: Part I. Social Work in Health Care, 2, 369-377.

Welsh, G.S. (1952). An anxiety index and an internalization ratio for the MMPI. Journal of Consulting Psychology, 16, 6572

Westbrook M.T., \& Viney, L.L. (1982). Psychological reactions to the onset of chronic illness. Social Science and Medicine, $16,899-905$.

Wood, P.H.N., \& Badley, E.M. (1981). People and disabilities (Monograph No.12). New York: World Rehabilitation Fund. Wright, B.A. (1960). Physical disability -- A psychological approach. New York: Harper \& Row.

Zuckerman, M. (1960). The development of an affect adjective checklist for the measurement of anxiety. Journal of Consulting Psychology, 24, 457-462.

Zung, W.W.G. (1965). A self-rating depression scale. Archives of General Psychiatry, 12, 63-70.

\section{Author Note}

The authors wish to thank Brian Bolton, Alfred Butler, Nancy Crewe, Arthur Dell Orto, Allen Heinemann, Donald Linkowski, Paul Lustig, Robert Pullo, Richard Roessler, Franklin Shontz, Jerome Siller, and Beatrice Wright for their valuable comments and suggestions during the development of the inventory.

\section{Footnotes}

${ }^{1}$ Frank, et al. (1987), for example, make a distinction between "phase" and "stage" theories. They view phase theories as those "which describe the onset of loosely organized psychological changes which are not exclusive" (p.44), where phases may partially overlap each other. Stage theories, on the other hand, are "those which describe discrete processes which are (categorically) exclusive" (p.44). A person, according to this model, can be in only one stage at a particular point in time.

${ }^{2}$ For reasons of practicality and ease of administration, the authors elected not to distinguish between the terms impairment and disability. The interested reader may refer to Livneh (1987) and Wood and Badley (1981) for discussion of these terms.

${ }^{3}$ Due to the voluminous amounts of data obtained from the separate analyses conducted for both time periods, only results from past reactions are reported here. Results based on comparisons of both time periods will be reported in future studies.

Dr. Hanoch Livneh is an Associate Professor and the Coordinator of the Rehabilitation Counseling Specialization, Department of Special Education and Counselor Education, at Portland State University, Portland, OR. Prior to assuming this position, he was the director of the Rehabilitation Counseling Program (1979-1989) and a professor of Counseling and Educational Psychology at Rhode Island College, Providence, RI.

Dr. Richard F. Antonak is an Associate Professor in the Department of Teaching Specialties, the University of North Carolina at Charlotte. Prior to assuming this position, he was a professor of Special Education, Developmental Disabilities Program, at the University of New Hampshire, Durham, NH. 